\title{
Vape shop retailers' perceptions of their customers, products and services: A content analysis
}

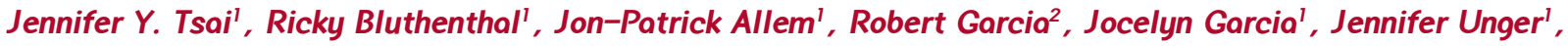 \\ Lourdes Boezconde-Gorbanati' ${ }^{\prime}$, Steve Y. Sussman'
}

\begin{abstract}
INTRODUCTION The popularity of electronic cigarettes (e-cigarettes) has spurred the growth of vape shops, but little is known about the retailers who may play an important role in the introduction and dissemination of vape products. In this paper we examine how retailers profile their customers and their perceptions of vaping, and the services their shops provide.

MEtHODS Semi-structured interviews were conducted with a convenience sample of retailers $(n=77)$ located across southern California. Open-ended questions were coded and analyzed using a content analysis approach.

RESULTS Three themes emerged from the content analysis: who vapes, why people vape, and the vape shop environment. Retailers profiled customers as friendly, health conscious, and interested in tobacco cessation or cessation maintenance. Retailers believed e-cigarettes were used recreationally or as products that help curb other addictive behaviors. While most retailers reported positive experiences with vaping, some reported potentially negative experiences including failed cessation attempts, dual use of e-cigarettes and combustible cigarettes, and increased nicotine dependence. Retailers reported that they regularly answer questions about vaping and believe their shops function as social lounges that are tied to other recreational activities.

CONCLUSIONS Retailers attach certain characteristics to their clientele, perceive certain health benefits associated with vaping, and seek to establish their shops as places that provide guidance on vape products as well as shops with a recreational aesthetic. As vape shops grow in popularity, additional research on, and regulation of, these retailers will be necessary. Education campaigns are needed to inform retailers of the benefits and consequences of vaping.
\end{abstract}

AFFILIATION
1 University of Southern
California, United States
2 Children's Hospital Los Angeles,
United States
CORRESPONDANCE TO
Jennifer Y. Tsai. University of
Southern California, 2001 N.
Soto Street, 3rd Floor 312-25,
90089 Los Angeles, United
States. Email: tsaijy@usc.edu
KEYwORDS
Vape shop, retail, electronic
cigarettes (e-cigarettes),
qualitative

Received: 27 January 2016 Revised: 7 April 2017 Accepted: 9 April 2017

\section{INTRODUCTION}

Electronic cigarettes (e-cigarettes) have recently grown in popularity, and specialty shops exclusively selling electronic cigarettes and e-cigarette related products, or vape shops, have proliferated to meet the growing interest in e-cigarettes ${ }^{1}$. Previous research shows that vape shops provide information on e-cigarette products and advice on issues such as the selection of flavors. Polosa et al. (2015) found that $69 \%$ of vape shop customers sought personalized e-cigarette support and advice from retailers, suggesting that retailers are important sources of information for customers ${ }^{2}$. As e-cigarette products evolve and user numbers increase, the role of vape shops in assisting customers with newer generations of e-cigarette products may become more important. For example, compared to disposable e-cigarettes, modifiable tank systems (customizable e-cigarettes that have removable tanks for refilling e-liquids) require assembly that may require instruction and demonstration by the retailer ${ }^{3}$. Despite the existence of nearly a thousand vape shops in the United States, little research has been conducted on these specialty stores and the people who work there ${ }^{4}$. Findings from the few published studies on vape shop retailers indicated that retailers believed e-cigarettes are safer than combustible cigarettes and safer than products that have been approved for cessation by the FDA (e.g. nicotine patch, gum, inhaler) ${ }^{7}$. Findings also reported that retailers frequently used e-cigarettes and claimed e-cigarettes helped them quit or cut down on combustible cigarettes ${ }^{7}$. Other research has shown that vape shop retailers use marketing strategies similar to those of the tobacco industry ${ }^{5-6}$ and that retailers often garner information 
from the Internet or from personal experiences, which result in the translation of misleading or incorrect information to customers ${ }^{8}$.

Given the instrumental role that retailers play in vaping norms and behaviors, it is important to better understand retailers' attitudes and behaviors toward vaping and their customers. The present study aims to explore how retailers profile their customers and their perceptions of vaping and vape shops.

\section{METHODS}

In the summer of 2014 in the Greater Los Angeles area 104 vape shops were identified using the convenience sampling frame from a previous Yelp study of vape shops located within various ethnic neighborhoods that reflect the diversity of Southern California (e.g. White, African-American, Latino, and Korean; see Sussman et al. 2014 for more details). Project staff for the current study visited these vape shops between the hours of 10 am to $5 \mathrm{pm}$ to ask vape shop retailers if they would be willing to participate in the study.

Of the 104 shops approached, 17 shops were out of business at the time of the interview, and 4 declined to be a part of the study. A total of 83 vape shop retailers consented to be interviewed; however, of these, six interviews were excluded from analysis. Shops were excluded from analysis if they did not identify themselves as a vape shop (e.g. tobacco distributor or tobacco shop - a shop also sells tobacco and tobacco-related products) or if project staff observed the sales of other tobacco-related products in a shop that self-identified as a vape shop. Thus, 77 interviews were retained for analysis.

Interviews were conducted with either the owner or manager or an employee (hereon referred to as retailers). All participants provided informed consent prior to the interview. Whenever possible, interviews were conducted verbally by trained project staff; otherwise, paper copies were left for participants to complete on their own and picked up by project staff later in the day. Forty-five surveys were filled-out by the participants on their own, and thirty-two surveys were verbally administered by project staff who annotated participant responses. The survey consisted of 30 closed-ended items and two open-ended questions. This study focused on survey questions that address retailers' perceptions of their customers, their perceptions of vaping practices, and their shops.

\section{Survey Development}

A draft of the interview questions was developed using questions from Project Towards No Tobacco (TNT) ${ }^{13-14}$, the Standardized Tobacco Assessment for Retail Settings (STARS) ${ }^{15}$, and results from a pilot study that observed vape shops and conducted brief interviews with vape retailers in Southern California. Study staff familiar with vape shops provided additional feedback to the initial questionnaire. The survey was then piloted at three vape shops outside the geographic scope of our current study. Changes suggested by the vape retailers from the pilot test were incorporated into the final questionnaire.

\section{Close-ended Questions}

Retailers were asked specifically, «What are the customers like who go to this vape shop: mostly males (yes or no); average age (indicate number), and most prevalent ethnicity (write-in)?» Retailers also were asked, «What type of social image would you hope your vape shop portrays? (check all that apply). Response choices were the following: «chic», «modern», «freedom», «revolutionary», «preppy», «sportsman», «a shop for everyone», «rebellious», «counterculture», «thoughtful», «intellectual», «a helpful place», and «friendly».

\section{Open-ended Questions}

Retailers were asked: «What best describes the customers who buy e-cigarettes from your shop.» In addition, retailers were asked if there was anything he/she wanted to say about vaping and/or their vape shop that was not asked.

All survey responses were recorded in English. Vape shop retailers were given a $\$ 50$ gift card for participating in the study. All study protocol was reviewed by the Institutional Review Board of the University of Southern California.

\section{Somple}

Retailers were White non-Hispanic (27\%), Asian non-Hispanic (27\%), Hispanic (9\%), and other race/ethnicity (36\%; e.g. Filipino, Middle Eastern). The average age of retailers was 27.8 years old ( $\mathrm{SD}=8.4$ years), and most were male $(86 \%)$. Retailers interviewed were owners - retailers who owned the shops (25\%), managers - retailers who managed the shops (39\%), clerks - retailers who helped with the sales of shop products (32\%), and other (e.g. builders, juice-tenders, bartender retailers who helped with specific aspects of vape guidance; $4 \%$ ).

\section{ANALYSIS}

Open-ended questions were coded using a qualitative, conventional content analysis approach ${ }^{10}$. Conventional content analysis uses an inductive approach to code qualitative data. An advantage of this approach is that the identification of themes is grounded within the data rather than on preconceived categories. The first author of the paper (JT) and a second reviewer (JG) conducted an iterative process of reviewing the interview data, which included the identification of key terms and 
concepts that can contribute to subcategories pertaining to the vaping community using Microsoft Excel (2007). Subcategories identified from the initial review were then combined into broader themes. Disagreements pertaining to the number and content of broader themes and subcategories were discussed until saturation was reached. Saturation occurred when both reviewers agreed that the existing themes and subcategories were comprehensive of the data.

After saturation was reached, both reviewers (JT and JG) independently coded the data again using the created codebook for established themes. Inter-coder agreement for the two reviewers was calculated via Cohen's kappa ${ }^{11}$ using SAS Version $9.4^{12}$. The Cohen kappa for the two reviewers was 0.93 (CI: $0.91,0.96)$, indicating almost perfect agreement.

Demographic information was analyzed using Microsoft Excel (2007).

\section{RESULTS}

Three themes were identified from our data: who vapes, why people vape, and vape shop environment. The minor themes and subcategories pertaining to each major theme derived from

Table 1. List of Major Themes, Minor Themes, and Subcategories Derived from Conventional Content Analysis ofOpen-Ended Questions

\begin{tabular}{|c|c|c|}
\hline Major Theme & Minor Theme & Subcategory \\
\hline \multirow{7}{*}{ Who Vapes } & \multirow{4}{*}{ Customer Profiles } & All Types \\
\hline & & $\begin{array}{l}\text { "Quitters" (previous smokers and older } \\
\text { individuals trying to quit smoking) }\end{array}$ \\
\hline & & $\begin{array}{l}\text { "Social Norm Vapers" (e.g., business } \\
\text { people/professionals, women, parents } \\
\text { who want kids to quit, new parents, } \\
\text { young adults/college students) }\end{array}$ \\
\hline & & Vape Enthusiast/»Aficionados \\
\hline & \multirow{3}{*}{$\begin{array}{l}\text { Customer } \\
\text { Characteristics }\end{array}$} & Curious/Trendy \\
\hline & & Friendly/Happy/Relaxed \\
\hline & & $\begin{array}{l}\text { Health Conscious/ Positive Life } \\
\text { Choices }\end{array}$ \\
\hline \multirow{5}{*}{ Why Vape } & \multirow{3}{*}{ Functionality } & $\begin{array}{l}\text { Smoking Alternative (for smoking } \\
\text { cessation or maintaining smoking } \\
\text { cessation) }\end{array}$ \\
\hline & & $\begin{array}{l}\text { Health Benefits (cravings - nicotine, } \\
\text { drugs, sugar) }\end{array}$ \\
\hline & & Recreational \\
\hline & \multirow[b]{2}{*}{ Experience } & Positive \\
\hline & & Nicotine Dependent \\
\hline \multirow{3}{*}{$\begin{array}{l}\text { Vape Shop } \\
\text { Environment }\end{array}$} & Anti-Smoking & Distinct from Tobacco Shop \\
\hline & Service & Vape Guidance \\
\hline & Atmosphere & Recreation (art gallery, bar, lounge) \\
\hline
\end{tabular}

the conventional content analysis of the open-ended questions are presented in Table 1.

\section{Who Vapes}

Retailers were asked to identify the demographics of the customers that frequented their shops. Most retailers reported that most of the customers were male (78\%), White (41\%) or Asian (22\%), and in their late twenties (mean age $=27.8$, $\mathrm{SD}=8.4$ ). In response to the open-ended question, "What best describes the customers who buy e-cigarettes from your shop?", retailers profiled customers based on their rationale for vaping and/or assigned character traits that are more nuanced than just their demographics.

Customer Profiles. Although many of the retailers suggested that e-cigarettes could be used by anyone, specific customer profiles were described. The most common types of customers encountered by retailers were those who wanted to quit smoking cigarettes or maintain cigarette smoking cessation, those we termed "quitters." Previous smokers were often older.

One retailer said, «80-95\% are those [customers] who want to quit [smoking]. From... athletes to brain surgeons. We get it all! All walks of life.»

"Older customers who want to quit..."

Another group was called "social norm vapers", individuals who interact in social settings where smoking is banned or undesirable were also frequent vape shop customers. These customers reportedly included business people, women, parents (e.g. parents who want their children to quit smoking and new parents of young children), and young adults/college students.

One retailer said, "We have sold to parents who caught the [ir] child smoking cigarettes, so they bought them a vape set up instead. Rather them vape than smoke cigarettes.»

A third group of customers were identified as «vape enthusiasts."

Another said, «One customer said, 'As of now, he does not feel like quitting vape because it's a hobby for him.'”

Customer Characteristics. Retailers often attributed certain qualities to their customers. Reoccurring themes were associated with positive traits describing e-cigarette users as friendly, relaxed, happy to stop cigarettes, and satisfied.

"They [customers] are very friendly and eager to switch over to e-cigarettes.» 
Figure. Type of Social Image Vape Shops Would like to Portray ( $\mathbf{N}=77)$

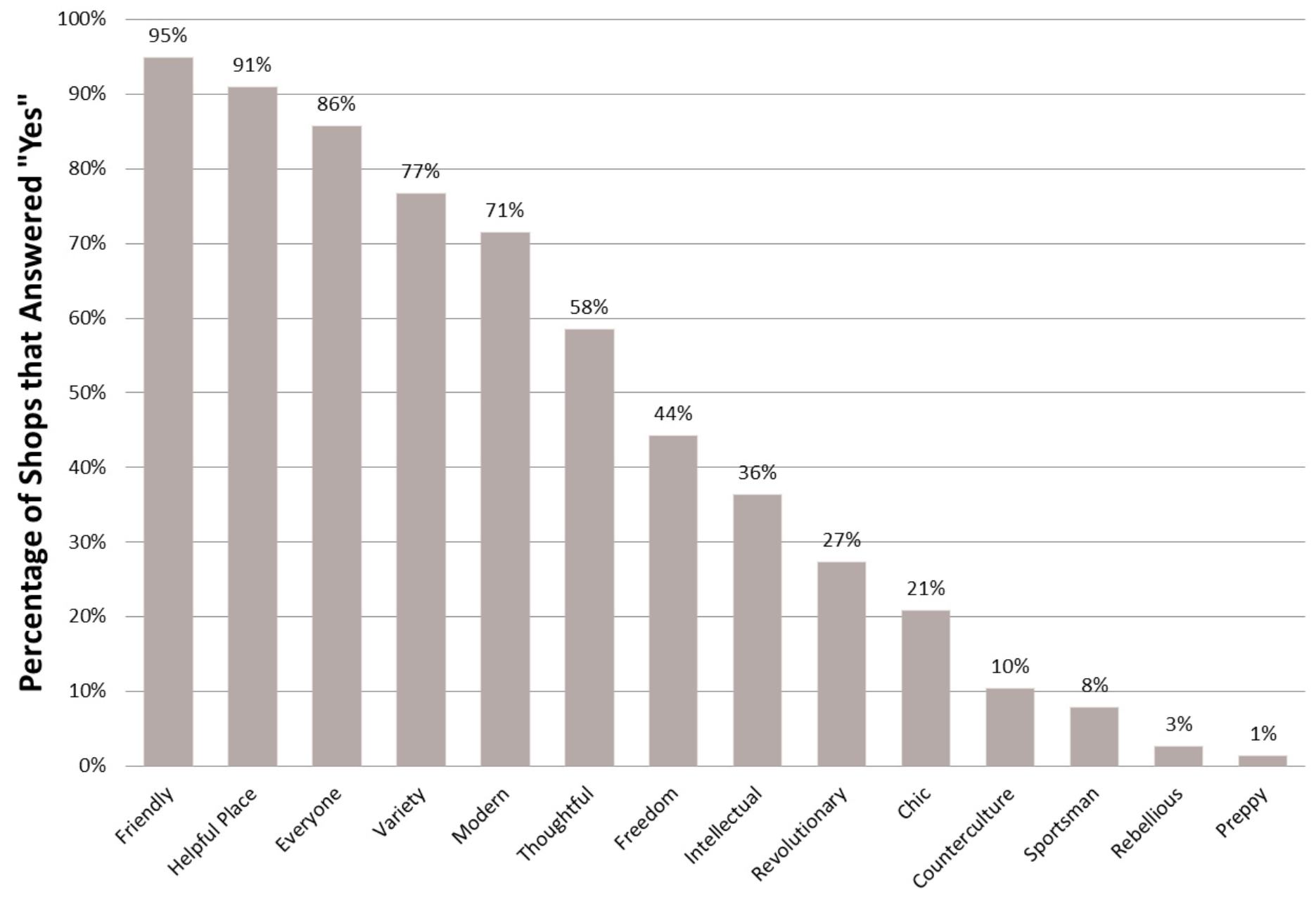

One retailer described their customers as, «... content, relaxed, friendly... happy to stop cigarettes.»

Furthermore, retailers considered their customers to be health conscious and included some interested in changing their habits.

«... [Customers] are friendly people who are trying to make positive life changes.»

Individuals that were new to vaping were deemed curious/ trendy.

«Some are people who want to learn about trending products.»

\section{Why Vope}

Functionality. While several retailers cite smoking alternative or cessation as the primary reason for vaping, some retailers suggested other health «benefits» that included e-cigarettes' ability to satisfy certain cravings that aid in weight loss and management of diabetes.
"My customers are from all walks of life, simply trying to quit cigarettes and/or maintaining their tobacco free life."

One retailer said, «Some diabetics come in the shop and use dessert or fruit flavors to get their 'sugar fix'... [this] has really helped them out.»

Another said, «Many girls who want to diet vape because they can vape a dessert flavor to satisfy their craving/sweet tooth and not add extra calories.»

The role of e-cigarettes as a recreational activity was also identified.

For example, «Additional information is available especially for those that want to turn 'vaping' into a hobby.»

Experience Perceptions regarding the functionality of vaping were highlighted by retailers when they shared personal or 
others' vaping experiences with little mention of the (scientific) validation of the suggested health claims. Two important themes (positive experiences and nicotine dependent) emerged when retailers discussed their own e-cigarette experiences and those of their customers. Positive experiences often revolve around cessation as a result of vaping.

One retailer said, "I was getting really bad coughs when I smoked and when I started vaping, it all went away. Feels like [my] airways are open and 'moisturized' now.»

Another said, «I used to be a smoker for 18 years... then quit after using vape products. My sense of smell and taste came back. Tried to smoke once again and it tasted very bad, couldn't even inhale. Vaping is better. Can't stop vaping and go back to smoking.»

E-cigarettes were believed to help individuals gradually reduce their nicotine dependence and were viewed as a much better alternative to stopping "cold turkey." While other types of nicotine reduction therapies were not discussed, some retailers alluded to vaping as more successful than other smoking cessation treatments.

One retailer said, «Nothing helped me quit except vaping... haven't returned to cigarettes since.»

Other, potentially problematic, experiences with e-cigarette use included failure to quit smoking, dual use of smoking cigarettes and vaping, and increasing nicotine dependence.

For example, «Got the dentist upstairs to partially stop smoking. Now he only smokes once in a while. I also stopped smoking, but have a cigarette once in a while when I run out of vape juice.»

Another retailer said, «I started at $0 \mathrm{mg}$ [of nicotine], but then went to $3 \mathrm{mg}$ or $6 \mathrm{mg}$ because I like the way nicotine makes me feel. It helps me focus. I am not a smoker though.»

\section{Vape Shop Environment}

Anti-Smoking. A distinction between smoking and e-cigarette use emerged from some of the discussions with retailers. Retailers did not want their vape shops to be perceived as tobacco shops and often strongly disagreed with cigarette smoking, while strongly encouraging e-cigarette use.

For example, "The [Vape shop name] is dedicated to a smoke-free lifestyle. Our devices are intended for entertainment purposes only. These are smoke free alternatives, not smoking cessation devices."
Another retailer said, «Shop owners ask distributors if they sell to tobacco shops as well. If they do, they will not purchase from the distributor.»

Service. The role of the vape shop and its employees as guides for new e-cigarette users were an important theme in analysis. Retailers often provided instruction on how to use e-cigarettes, introduced different «juice» flavors and products, and helped troubleshoot problems with setting up vaping equipment.

For example, «Support and consultations involve walking customers through purchasing their first 'set up'... purchasing e-juices and showing customers how to prepare the 'set up' with e-juice. Additional information about e-cigarette equipment is available especially for those that want to turn vaping into a hobby.»

Another employee said, «I call myself a bartender because I assist customers with juices and builds.»

Atmosphere. Retailers hoped to establish their shops as recreational spaces distinct from tobacco shops and tied to other recreational activities.

For example, one retailer stated, "From the beginning this shop has always wanted to be about vaping and art. A gallery that anyone can enjoy while lounging."

"[This is a ...] vape shop and gallery. [We] put on shows and every 2nd Saturday and participates in art week..... have DJ and wine for customers to come in.»

The vape shop environments reported by retailers were aligned with the social images retailers wanted their vape shops to portray, as seen in Figure 1. Most retailers said they wanted the social image of their vape shops to be friendly (95\%), a helpful place $(91 \%)$, and a place for everyone (86\%). A majority or more of vape-shop retailers also said they wanted to portray modern (71\%), thoughtful (58\%), intellectual (60\%) and diverse (variety) social images (77\%). Almost all of the vape shop retailers reported that they did not want their vape shops to be considered "sportsman", "preppy", or "rebellious".

\section{DISCUSSION}

Findings indicated that vape shop retailers attach certain characteristics to their clientele, perceive certain health benefits associated with vaping, and provide various services (e.g. assistance with setting up vaping equipment, and exposing 
existing and naïve users to new vaping products). Vape shop retailers described their customers with positive attributes such as friendly and satisfied. In addition, retailers believed vape shops are places to socialize and are distinct from tobacco shops.

Retailers seek to establish vape shops as spaces where people can mingle and be entertained. Customers most frequently patronizing these shops in Los Angeles, California were reported to be previous smokers (92\%) and young adults (16\%). Retailers' expectations and perceptions of their services and customers, respectively, may be indicative of marketing strategies utilized by vape shops to attract customers. An earlier study by Cheney et al. (2015) on vape shop owners' marketing strategies in Oklahoma City, Oklahoma found that vape shop owners used marketing strategies that targeted previous smokers and college students ${ }^{8}$. They also found that vape shops often sponsor events (e.g. cloud chasing contests, display local artwork) and create atmospheres that extend beyond vaping products as a marketing device to generate a sense of community among customers. If retailers indeed identify customers as "social norm vapers" (e.g. professionals or young adults), and attribute certain qualities (e.g. trendy) with their customers, this may help explain why vape shops are using marketing strategies that target individuals who may vape to maintain a specific persona and are sponsoring events that vape retailers may believe reflect the norms and behaviors of their customers ${ }^{16}$.

Many retailers provide guidance on vaping products and share personal vaping experiences. This study supports previous findings by Cheney et al. (2015) that retailers' knowledge and perceptions towards vaping are often derived anecdotally ${ }^{4}$. That is, most of the vaping experiences and information retailers discussed are anecdotal, stemming from their personal experiences or the experiences of other customers, and little was said about how information was verified. For example, vape retailers perceived e-cigarettes as a harm-reducing alternative to combustible cigarettes and other health problems (e.g. dieting) because vaping had helped them or others quit smoking cigarettes or satisfy sugar cravings. Retailers who garner vaping related information from anecdotal sources (e.g. personal and customer vaping experiences, online) may elicit consequences such as support for unverified health claims regarding e-cigarette use and the renormalization of nicotine use. In addition, when retailers provide guidance on vaping products, they may, in some ways, act like (smoking) cessation counselors. Allowing vape shop retailers to provide such services raises concerns, especially when retailers lack the proper or formal training to do so and when they have a vested interest in getting customers to use different products.

These findings further highlight the importance of educating retailers about the health consequences of vaping and possibly training retailers in some forms of cessation counseling, if vape shops are incorporated into a harm reduction strategy. For that purpose, convenient and reliable sources of education and training would be needed to help retailers navigate difficult medical and legal jargon and vape-related research findings. Educational initiatives might be designed and implemented for that purpose by the Food and Drug Administration (FDA) or other entities, such as local and state government agencies, the Center for Disease Control, and academic research institutions, depending on the future characteristics and scope of vape shops and retailers. These might include workshops to inform retailers about the legal ramifications of making unverified health claims and the health consequences of using a nicotine product. Given the diversity of vape shop retailers, educational campaigns should also be conducted in various languages and at the appropriate (health) literacy levels.

\section{LIMITATIONS}

Although the response rate was high, this study's sample of vape shops and findings is not representative of vape shops across Southern California or elsewhere. Retailers who agreed to be interviewed tended to be enthusiastic about vaping. These individuals' positions and experiences with e-cigarettes may differ from those retailers who did not participate in the study. The themes identified in the study came from two open-ended questions. A more structured qualitative interview that asks more detailed and probing questions regarding vaping (e.g. «What services do you (the vape shop) provide?» and «What types of customers do you (or your vape shop) hope to attract?" may provide a better picture of the expectations vape shop retailers associate with their services and customers. Further, participants were asked to provide descriptions of customers and to summarize their attitudes and beliefs; research collecting such information from e-cigarette users directly is needed. The qualitative analysis employed herein utilized an inductive process that may be subjected to biases held by the individuals that coded the data.

\section{CONCLUSIONS}

E-cigarette retailers may play a significant role in how e-cigarettes are used, yet there are few studies on this group. Research that replicates and builds upon the current approach are need in other geographic areas. More qualitative research is needed to determine whether the tailored services provided by vape shop retailers and the unique environmental settings provided by vape shops attract different types of customers and influence their vaping-related beliefs and behaviors. While this study was 
unable to determine whether retailer expectations are associated with marketing strategies, further research should examine whether retailer perceptions about their customers and services manifests themselves into vape shop marketing strategies, or vice versa. Further investigation of the interaction between the retailer and customer could also help explain how retailers' contribute to consumers' views and their knowledge of vaping, and may indicate needed areas for surveillance of vape shops and their retailers.

\section{REFERENCES}

1. Lee, Y. O., \& Kim, A. E. (2014). 'Vape shops' and 'E-Cigarette lounges' open across the USA to promote ENDS. Tobacco Control. Advance online publication.

doi: 10.1136/tobaccocontrol-2013-051437.

2. Polosa, R., Caponnetto, P., Cibella, F., \& Le-Houezec, J. (2015). Quit and Smoking Reduction Rates in Vape Shop Consumers: A Prospective 12-Month Survey. International Journal of Environmental Research and Public Health, 12(4), 3428-3438. doi: 10.3390/ijerph120403428.

3. Grana, R., Benowitz, N., \& Glantz, S.A.(2014). E-cigarettes a scientific review. Circulation, 129(19):1972-1986.

4. Dai, H., \& Hao, J. (2016). Geographic density and proximity of vape shops to colleges in the USA. Tobacco control, tobaccocontrol-2016.

5. Hsu, R., Myers, A. E., Ribisl, K. M., \& Marteau, T. M. (2013). An observational study of retail availability and in-store marketing of e-cigarettes in London: potential to undermine recent tobacco control gains?. BMJ open, 3(12), e004085.

6. Cheney, M., Gowin, M., \& Wann, T. F. (2015). Marketing practices of vapor store owners. American journal of public health, 105(6), e16-e21. doi: 10.2105/AJPH.2015.302610.

7. Allem, J. P., Unger, J. B., Garcia, R., Baezconde-Garbanati, L., \& Sussman, S. (2015). Tobacco Attitudes and Behaviors of Vape Shop Retailers in Los Angeles. American Journal of Health Behavior, 39(6), 794-798. doi: 10.5993/AJHB.39.6.7.

8. Cheney, M. K., Gowin, M., \& Wann, T. F. (2015). Vapor store owner beliefs and messages to customers. Nicotine \& Tobacco Research, ntv129.

9. Sussman, S., Garcia, R., Cruz, T. B., Baezconde-Garbanati, L., Pentz, M. A., \& Unger, J. B. (2014). Consumers' perceptions of vape shops in Southern California: an analysis of online Yelp. Tobacco Induced Diseases, 12(1):22. doi: 10.1186/s12971-014-0022-7.

10. Hsieh, H.F., \& Shannon, S. E. (2005). Three approaches to qualitative content analysis. Qualitative health research, 15(9), 1277-1288.

11. Viera, A. J., \& Garrett, J. M. (2005). Understanding interobserver agreement: the kappa statistic. Fam Med, 37(5), 360-363.

12. SAS Institute Inc. Cary, NC: SAS Institute Inc; 2014-2015. SAS/ STAT Software version 9.
13. Barovich, M., Sussman, S., Galaif, J., Dent, C. W., \& Charlin, V. L. (1988). School and store interview-to-observation studies, phase 1: Assessment studies A and B, project towards no tobacco use (TNT). In Technical Report\# 88-TNT-02. Institute for Health Promotion and Disease Prevention Research, University of Southern California Pasadena.

14. Sussman, S., Hahn, G., Dent, C. W., Stacy, A. W., Burton, D., \& Flay, B. R. (1993). Naturalistic observation of adolescent tobacco use. International Journal of the Addictions, 28(9), 803-811.

15. The Standardized Tobacco Assessment for Retail Settings (STARS) survey. (2014, June 16). State and Community Tobacco Control Research. Available at: http://sctcresearch.org/blog/standardizedtobacco-assessment-for-retail-setting/. (accessed May 2017)

16. Chu KH, Allem JP, Cruz TB, Unger JB. Vaping on Instagram: cloud chasing, hand checks and product placement. Tobacco Control. 2016 Sep 22:tobaccocontrol-2016.
ACKNOWLEDGEMENTS

This work was supported, in part, by grant number P50CA180905 from the National Cancer Institute $(\mathrm{NCl})$ and Food and Drug Administration (FDA) Center for Tobacco Products (CTP), and from discretionary account funding. The NCl/FDA funding covered only aspects of the project that were under FDA regulatory authority at the time of data collection. The content is solely the responsibility of the authors and does not necessarily represent the official views of $\mathrm{NCl}, \mathrm{NIH}$ or the FDA.

CONFLICT OF INTERESTS The authors have completed and submitted the ICMJE Form for Disclosure of Potential Conflicts of Interest and none were reported.

FUNDING

There was no source of funding for this research.

PROVENANCE AND PEER REVIEW

Commissioned;

externally peer reviewed. 